\title{
Phytoremediation of petroleum polluted soil
}

\author{
Wang Jing *, Zhang Zhongzhi, Su Youming, He Wei, He Feng and Song \\ Hongguang
}

School of Chemical Science \& Engineering, China University of Petroleum, Beijing 102249, China

\begin{abstract}
An experimental study of the rhizosphere effect on phytoremediation of petroleum polluted soil was carried out with three species of grasses, namely Pannicum, Eleusine indica (L.) Gaerth, and Tall Fescue. After a period of 150 days, this pot experiment showed that the rhizosphere of these three species accelerated the degradation of petroleum hydrocarbons to different extents. The results showed that the number of microorganisms in the rhizosphere increased by three orders of magnitude. The induction of the plant rhizosphere and the coercion influence of petroleum changed the species and activity of microorganisms. The degradation of petroleum hydrocarbons in the rhizosphere was 3-4 times that in unplanted soil. The dehydrogenase activity in the rhizosphere was 1.61-2.20 times that in unplanted soil, but the catalase activity was $0.90-0.93$ times that in unplanted soil, and soil moisture content increased by $5 \%$ compared with the unplanted soil.
\end{abstract}

Key words: Phytoremediation, rhizosphere, microbial number, dehydrogenase activity, catalase activity, petroleum hydrocarbon degeneration

\section{Introduction}

Many developing nations face serious soil contamination problem. As a result of human economic activity, large quantities of soil have been contaminated with petroleum products (Kaimi et al, 2006). Petroleum contaminated soil causes pollution of local ground water by organics, threatens the safety of potable water, limits the use of ground water, causes enormous economic loss and ecological disaster, and destroys agricultural production (Wang et al, 2007; Xu et al, 2006). Soil pollution has become an environmental problem that affects human beings (Escalante-Espinosa et al, 2005). Remediation of oil polluted soil has attracted worldwide attention. Phytoremediation is regarded as a costeffective method for removal of petroleum from soil, and has a great potential in remediation of soil contaminated with petroleum (Joner et al, 2002; Ryan et al, 2001). In addition, this method is not destructive and could remedy the soil structure and recover the biological environment (Maria et al, 2002). Phytoremediation of polluted soil has been applied successfully. Because of their sessile nature, plants develop the ability to resist a wide range of environmental assaults, plants enhance the remediation of petroleum-containing soils by various processes, including elimination, destruction or sequestering hazardous substances from the environment (Maila and Cloete, 2002; Vervaeke et al, 2003). Laboratory and pot experiments demonstrated that plants enhanced the dissipation of poly-aromatic hydrocarbons (PAHs) when compared to unplanted controls(Joner et al, 2002; Chen et al, 2003). Phytoremediation field trials showed that the reduction

*Corresponding author. e-mail: swhgwj898@cup.edu.cn

Received July 19, 2007 of petroleum hydrocarbons in the rhizosphere was accelerated (Chen et al, 2003; Glick, 2003). Liste and Alexander (2000) reported that the degradation of pyrene can be promoted by nine different plant species, including three field crops, three horticultural plants, and three pine seedlings. The key issue for successful phytoremediation was the application of plant species that have the ability to proliferate in highly contaminated soil.

The aim of the present study was to investigate the effect of three different plant species on microbial remediation of petroleum polluted soil. The contaminated soil used in this study was from Dagang Oil Field, and Pannicum, Eleusine indica (L.) Gaerth, and Tall Fescue were selected for remediation of the petroleum polluted soil. The changes of microbial number, petroleum content, dehydrogenase activity, catalase activity in the soil and the moisture of the soil were monitored regularly during the pot experiment. The possible factors for these changes are discussed in this paper. The influence on the degradation of hydrocarbons in petroleum polluted soil is presented, providing a theoretical and technical support for phytoremediation of petroleum polluted soil.

\section{Materials and methods}

\subsection{Polluted soil for experiment}

The petroleum polluted soil was from Dagang Oil Field, Bohai Bay Basin, East China. The soil was sieved with a $5 \mathrm{~mm}$-nylon screen after solar drying. The characteristics of the soil are as follows: $\mathrm{pH} 8.9$, total organic carbon 72.5 $\mathrm{mg} \cdot \mathrm{kg}^{-1}$, total N $4.15 \mathrm{mg} \cdot \mathrm{kg}^{-1}$, total P $0.42 \mathrm{mg} \cdot \mathrm{kg}^{-1}$, sand $7.8 \%$ (by weight), heavy clay $5.4 \%$ (by weight) and oil content 8,247 
$\mathrm{mg} \cdot \mathrm{kg}^{-1}$.

\subsection{Plant for remediation of petroleum polluted soil}

Three grass species, Pannicum, Eleusine indica (L.) Gaerth, and Tall Fescue, were selected for phytoremediation. Tall Fescue was used for phytoremediation and showed to be more tolerant of petroleum than other tested species in our previous work. Pannicum and Eleusine indica (L.) Gaerth were new tested species.

\subsection{Experimental procedures}

First, the petroleum polluted soil was mixed fully with pollutant-free soil to reduce the oil content to $5,000 \mathrm{mg} \cdot \mathrm{kg}^{-1}$. The experimental pot had a height of $33 \mathrm{~cm}$ and a diameter of $23 \mathrm{~cm}$. Each pot contained $12 \mathrm{~kg}$ soil. At the beginning of experiment, the soil in the pot was irrigated until it was saturated. The pot experiment was conducted outdoors in August and September. From October to December, the experiment was conducted indoors. Two grams of seeds were soaked separately in $75 \%$ (v/v) ethanol for 30 minutes. Then, the seeds were washed with clear water then soaked in clear water for 3-4 days. When the white radicles appeared, the seeds were transplanted to the pot. During the experiment period, the irrigation frequency and the volume of irrigation water were controlled to prevent petroleum in the soil from washing out. The irrigation interval was once every two days, the volume of irrigation water was $50 \mathrm{~mL}$ for each pot. Simultaneously an unplanted pot was used as a control soil and operated in the same procedures.

\subsection{Chemical analysis}

Soil was collected for analysis at $0,30,60,90,120$ and 150 days. The sample soil was taken from a depth of $7 \mathrm{~cm}$ under ground near the root, according to the plum blossom method (He, 2001). Five samples were taken for analysis at one time. Soil samples were analyzed for moisture, dehydrogenase activity, catalase activity, microbial number and petroleum content.

\subsubsection{Measurement of petroleum content of soil}

The petroleum content of the soil was measured with the Soxhlet method (US EPA, 1996). First, the soil was dried under vacuum. Then petroleum was extracted from a $5 \mathrm{~g}$ sample of soil using $\mathrm{CCl}_{4}$ as solvent for 6-8 hours until $\mathrm{CCl}_{4}$ became colorless. The extract was diluted with four parts of $\mathrm{CCl}_{4}$ to $1 / 5$. Finally, the diluent was injected into an oil content tester OIL-20A to determine the petroleum content.

\subsubsection{Measurement of characteristics of soil}

The moisture content of soil was measured by the loss of water at $40{ }^{\circ} \mathrm{C}$ and $-0.08 \mathrm{MPa}$; The $\mathrm{pH}$ of soil was measured by a glass electrode apparatus (Sartorius PB-10). The total organic carbon of soil was measured with the potassium dichromate method, the total $\mathrm{N}$ with the Kjeldahl method and the total $\mathrm{P}$ with sodium hydroxide digestion method (Liu, 2001).

\subsubsection{Measurement of microbial levels in rhizosphere soil}

The microbial population was measured with the spread plate counting method. The incubation media used for isolation of bacteria was peptone, beef-extract and agar.
Plates were incubated for 3 days at $35^{\circ} \mathrm{C}$ prior to counting the colony forming-units (cfu).

\subsubsection{Enzyme activity in rhizosphere soil}

The dehydrogenase activity in the rhizosphere soil was determined according to the triphenyl tetrazolium chloride method (Hayano, 1997). For this, $1 \mathrm{~g}$ of the soil was cultivated in $0.2 \mathrm{~mL}$ of $0.4 \%$ triphenyl tetrazolium chloride solution with $50 \mu \mathrm{l}$ of $1 \%$ glucose for $24 \mathrm{~h}$ at $27^{\circ} \mathrm{C}$ in a dark environment. The TF (triphenyl formazan) formed by enzyme reactions was extracted by using $10 \mathrm{~mL}$ of methanol, shaken vigorously for 1 minute, and then filtered. Triphenyl formazan was measured spectrophotometrically at $486 \mathrm{~nm}$.

The catalase activity was determined according to the potassium permanganate method (Guang, 1986). For this, $1 \mathrm{~g}$ of the soil was titrated using $\mathrm{KMnO}_{4}$ solution at a concentration of $1 \times 10^{-3} \mathrm{~mol} \cdot \mathrm{L}^{-1}$.

\section{Results and analysis}

\subsection{Change of microbial activity}

In the phytoremediation process, the microbial population in the rhizosphere soil was measured. The microbial numbers in planted and unplanted soils were measured by the most probable number method, and the results are shown in Fig. 1.

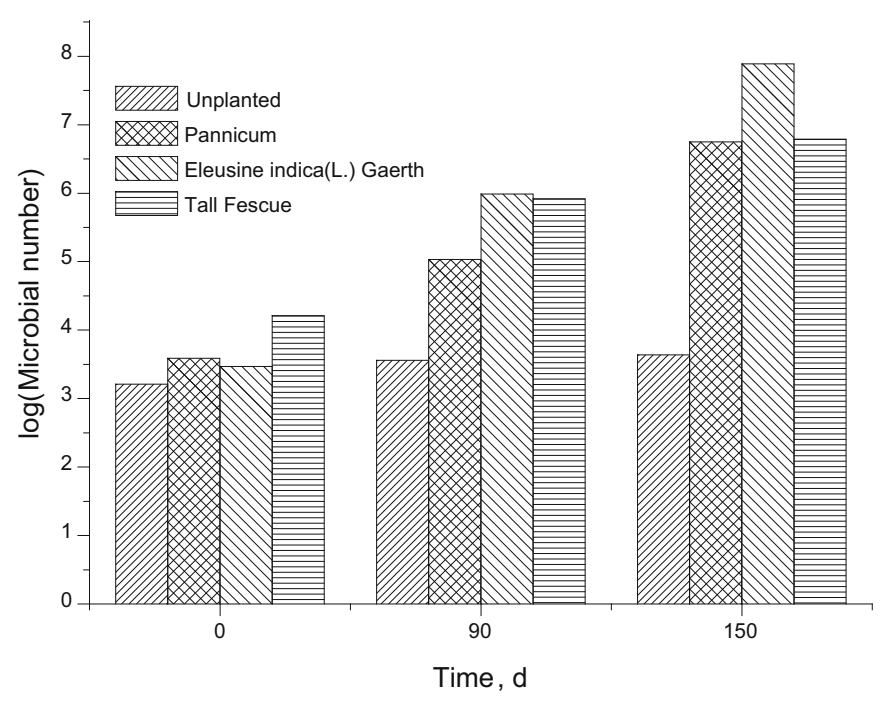

Fig. 1 Change of microbial number

Fig. 1 shows that in the 150 days remediation process the number of microorganisms in the rhizosphere increased by three orders of magnitude compared to the unplanted soil, and the number of microorganisms increased by two orders of magnitude after 90 days of remediation. From 90 days to 150 days, the microbial number increased by one order of magnitude. The numbers of microbes were different between the earlier (from 0 to 90 days) and the later period (from 90 to 150 days). Except for the different intervals of measurement time, the reason might be that the secretion of plant roots in the earlier period was more than that in the later period. Plant roots release compounds including monosaccharides, amino acids, enzymes, aliphatics, and 
aromatics that stimulated the growth of specific microbial communities (Crarela et al, 2000). The interactions between plants and microbes in the rhizosphere are complex and in some cases mutually beneficial to both organisms (Hedge et al, 1996). With increasing microbial levels, the species and activity of microorganisms also changed. The influence of petroleum pollutants and plant rhizosphere promoted the increase of microorganisms that could degrade petroleum hydrocarbons. Thus, the microorganisms that degraded petroleum became the predominant microorganisms in the rhizosphere environment. Moreover, in order to adapt to the surrounding environment, the plant also could secrete allelopathic substances similar to the pollutant. The types of the microorganisms changed while this allelopathic substance stimulated the resistance of the microorganism to the petroleum pollutant (Merkl et al, 2006).

\subsection{Degradation of petroleum hydrocarbons in plant rhizosphere}

In the plant rhizosphere the soil environment was improved compared to unplanted soil, so that the growth and activity of microorganisms were promoted. Simultaneously, with the growth of the plant roots, the soil became loose. And the oxygen needed in oxidation of pollutant was transported into deeper levels of soil along the root. In addition, the plants root itself secreted organic compounds and enzymes. All of these factors were favorable to the degradation of petroleum hydrocarbons. The petroleum content in soil was measured as shown in Fig. 2.

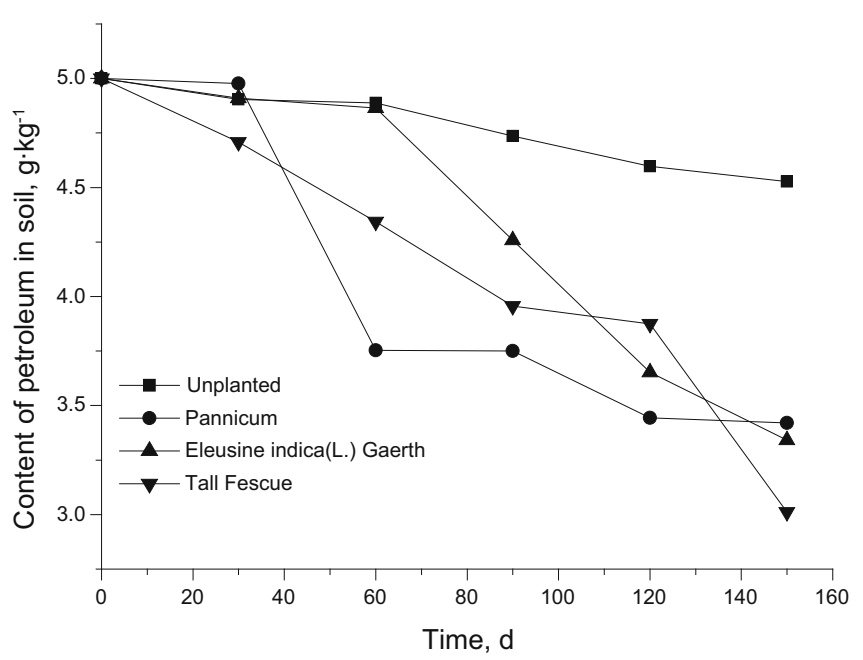

Fig. 2 Content of petroleum in soil

In the unplanted soil, the degradation of petroleum hydrocarbons was only about $10 \%$. But the degradation of petroleum hydrocarbons reached $30 \%-40 \%$ in the planted soil, three to four times higher than that in the unplanted soil. Therefore it was concluded that the degradation of petroleum hydrocarbons in the planted soil was stimulated by plant roots. Moreover, the degradation of petroleum hydrocarbons in different plant rhizosphere environments was mainly related to the diversity of plant roots and their secretion, i.e. the enzymes. Loss of petroleum hydrocarbons through direct plant uptake was negligible. The reason why the degradation rate of petroleum hydrocarbons was enhanced in the rhizosphere was that the secretion of plant roots promoted microbial populations and their activity. The increased microbial population induced by the rhizosphere could improve the degradation of petroleum hydrocarbons. So this relationship between plant and microbes was favorable to degradation of petroleum hydrocarbons in the planted soil.

\subsection{Change of dehydrogenase activity in soil}

The plant root system and microorganisms all could produce various enzymes. The enzymes could catalyze the oxidization reaction of petroleum hydrocarbons, and dehydrogenase was most important. Dehydrogenase was vital in the outset stage of the oxidation process of petroleum hydrocarbons. It could activate the hydrogen atoms of the petroleum hydrocarbons and transport the hydrogen atom to a specific hydrogen acceptor, and then the petroleum hydrocarbons were oxidized and transformed. In many instances, the degradation or transformation of petroleum hydrocarbons by plant roots and microorganisms started from dehydrogenation. Therefore, the activity of dehydrogenase could reflect the degradation activity of petroleum hydrocarbons by plant root system and microorganism. The change of dehydrogenase activity is shown in Fig. 3.

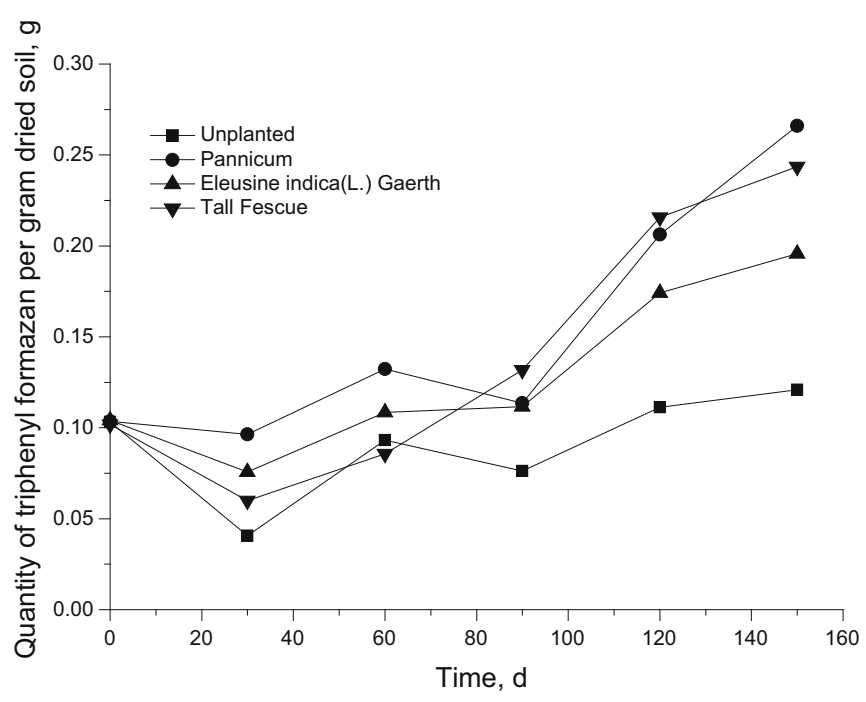

Fig. 3 Change of dehydrogenase activity in the rhizosphere

Fig. 3 shows that in the remediation process, the dehydrogenase activity in the planted soil was 1.61-2.20 times that in the unplanted soil. The enhancement of dehydrogenase activity reflected that the degradation of petroleum hydrocarbons was improved. It indicated that the plant rhizosphere was favorable to the degradation of petroleum. The reason why the dehydrogenase activity was enhanced might be that the microorganisms could adapt themselves to the adverse environment created by petroleum pollutants and use petroleum pollutants as a new 
carbon source. Hence, the activity of microorganisms was improved, and specifically the activity of dehydrogenase was also improved. This was also proved by the enhancement of dehydrogenase activity in the unplanted soil. The proliferation of plant root, increase of metabolite and sufficient water all promoted the microorganisms activity. This was the reason why the dehydrogenase activity in the rhizosphere was higher than in the unplanted soil. In the early 30 days of remediation, the dehydrogenase activity dropped in both planted soil and unplanted soil. It was caused mainly by the drop of temperature outdoors in autumn, showing a negative relationship between dehydrogenase activity and temperature. Low temperatures are not favorable for microorganism activity and degradation of petroleum hydrocarbons by the plant rhizosphere.

\subsection{Change of catalase activity in soil}

Catalase exists widely in microorganisms and plant root cells in soil. It is formed in the process of biological breathing and in the biochemical reaction of organic matter. It could promote the decomposition of hydrogen peroxide, preventing hydrogen peroxide from poisoning the organism. The catalase activity was closely related to the respiration of soil and the activity of microorganism, and reflected the reactive intensity of soil microbe to a certain extent. So catalase is an important enzyme for studying the characteristics of soil biology.

Fig. 4 shows that the catalase activity was reduced in the phytoremediation process and was lower in the planted soil than in the unplanted soil. The catalase was produced by aerobic bacteria, since this enzyme does not exist in anaerobic bacteria. In the rhizosphere enbironment, plant roots can potentially increase oxygen levels of soil compared to unplanted soil by increasing the permeability of the soil. As a result, more aerobic bacteria should exist, and the catalase activity in the planted soil could be higher than that in the unplanted soil, but the fact was quite the contrary. The reason might be as follows: (1) The intermediate metabolites

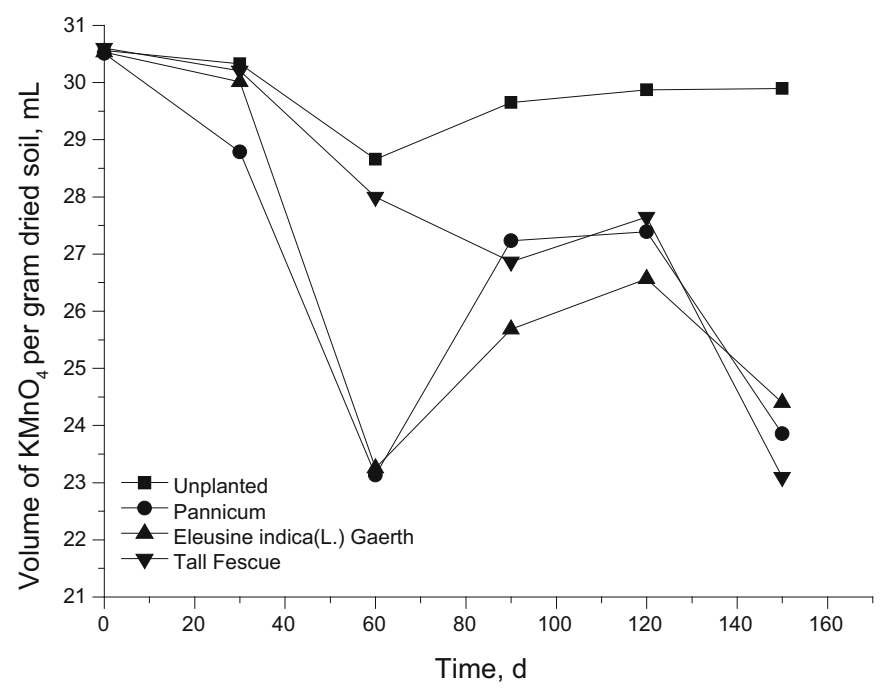

Fig. 4 Change of catalase activity in soil

Notes: Catalase acivity is expressed as the $1 \times 10^{3} \mathrm{~mol} \cdot \mathrm{L}^{-1}$ potassium permanganate equivalent per gram dried soil produced in the degradation of petroleum hydrocarbons might be poisonous and restrained the catalase from forming. (2) The microbial species changed in the plant rhizosphere environment, and the number of bacteria that could excrete catalase decreased.

\subsection{Influence of plant rhizosphere on soil moisture}

The influence of the plant rhizosphere on soil moisture is shown in Fig. 5.

Fig. 5 shows that moisture content increased obviously in the planted soil. When the irrigation frequency and volume of irrigation water were the same, soil moisture rose from $13 \%-14 \%$ to $20 \%$ gradually in the phytoremediation process in the planted soil, but the moisture content in the unplanted soil fluctuated between $15 \%$ and $16 \%$. The reason was that the growth of plant roots promoted the soil to form an effective circuit for water movement. And the plant root system improved the permeability of soil for water. The plant root system could prevent water from flowing out by absorption and fixation of water, thus the moisture content in the soil satisfied the demand of microorganisms and plants and was favorable to the degradation of petroleum hydrocarbons in the soil.

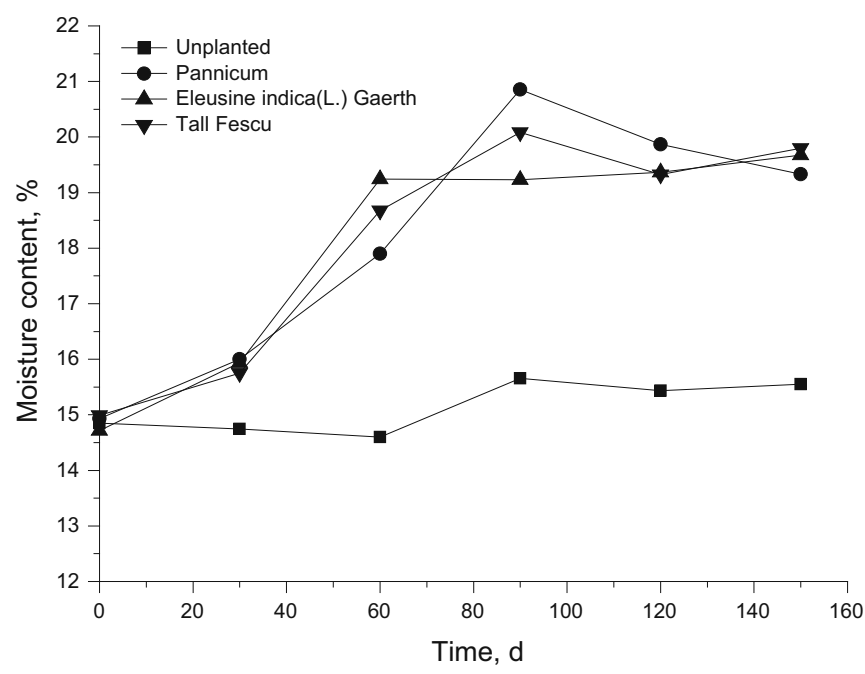

Fig. 5 Influence of plant rhizosphere on soil moisture

\section{Conclusion}

Three species of plants, i.e. Pannicum, Eleusine indica (L) Gaerth, and Tall Fescue, selected for phytoremediation of petroleum polluted soil accelerated the degradation of petroleum hydrocarbons to different extents. Two new species, Pannicum and Eleusine indica (L.) Gaerth, had remarkable remediation effect similar to Tall Fescue. The number of microorganisms in the rhizosphere increased by three orders of magnitude. The action of the plant rhizosphere and the influence of petroleum hydrocarbons changed the species and activity of microorganisms. The degradation of petroleum hydrocarbons in the planted soil was 3-4 times that in the unplanted soil. The dehydrogenase activityin the planted soil was 1.61-2.20 times that in unplanted soil, but the catalase activity was $0.90-0.93$ times that in the unplanted soil. The 
plant root system could increase the moisture content in the soil by absorption and fixation of water. The moisture content in the planted soil increased by $5 \%$ compared with that in the unplanted soil.

\section{Acknowledgment}

This work was supported by the National Natural Science Foundation of China under grant No. 40672211.

\section{References}

Chen Y C, Katherine Banks M and Paul Schwab A. Pyrene degradation in the rhizosphere of Tall Fescue (Festuca arundinacea) and Switchgrass (Panicum virgatum L). Environ. Sci. Technol. 2003. 37(24): 5778-5782

Crarela G J, Plaza C C and Soler R P. Long-term effects of municipal solid waste compost application on soil enzyme activities and microbial biomass. Soil. Biol. Biochem. 2000. 32: 1907-1913

Escalante-Espinosa E, Gallegos-Martínez M E, Favela-Torres E, et al. Improvement of the hydrocarbon phytoremediation rate by Cyperus laxus Lam. Inoculated with a microbial consortium in a model system. Chemosphere. 2005. 59(3): 405-413

Glick B R. Phytoremediation: synergistic use of plants and bacteria to clean up the environment. Biotechnol. Adv. 2003. 21(5): 383-393

Guang S Y. Soil Enzyme and Research Method. 1986. 323-328. Beijing: Agricultural Press (in Chinese)

Hayano, K. Measurement of soil enzyme activity. In: Hattori T, Nishino $\mathrm{T}$ and Miyashita K (Eds.), Soil Microbiological Society of Japan, Experimental Methods in Soil Microbiology-New Edition. 1997. 365-367. Youken-dou, Tokyo (in Japanese)

He S Y. The analysis and monitor of environment pollutant. 2001. 77-80. Beijing: Chemical Industry Press (in Chinese)

Hedge R S, Fletcher J S. Influence of plant growth stage and season on the release of root Phenolics by mulberry as related to development of phytoremediation technology. Chemosphere. 1996. 32: 2471-2479
Joner E J, Corgie S C and Amellal N. Nutritional contributions to degradation of polycyclic aromatic hydrocarbons in a simulated rhizosphere. Soil Biol. Biochem. 2002. 34: 859-864

Kaimi E, Mukaidani T, Miyoshi S, et al. Ryegrass enhancement of biodegradation in diesel-contaminated soil. Environmental and Experimental Botany. 2006. 55(1-2): 110-119

Lis te $\mathrm{H} \mathrm{H}$ and Alexander M. Plant-promoted pyrene degradation in soil. Chemosphere. 2000. 40: 7-10

Liu F Z. Practical handbook of agriculture environment monitoring. 2001. 88-177. Beijing: Chinese Standard Press (in Chinese)

Maila M P and Cloete T E. Germination of Lepidium sativum as a method to evaluate polycyclic aromatic hydrocarbons (PAHs) removal from contaminated soil. Int Biodeterior Biodegrad. 2002. 50(2): 107-113

Maria T, Thomas G R and Angela S. Bacterial rhizosphere populations of black poplar and herbal plants to be used for phytoremediation of diesel fuel. Soil Biology and Biochemistry. 2002. 34(12): 1883-1892

Merkl N, Schultze-Kraft R and Arias M. Effect of the tropical grass Brachiaria brizantha (Hochst.ex A. Rich.) Stapf on microbial population and activity in petroleum contaminated soil. Microbiol. Res. 2006. 161(1): 80-91

Ryan K M, Mary K and Friestone M. Enhanced phenanthrene biodegradation in soil by slender oat root exudates and root debris. Environ Qual. 2001. 30:1911-1918

US EPA. Test methods for evaluating solid wastes physical/chemical methods. 1996. 99-107. Environmental Protection Agency, Washington, DC

Vervaeke P, Luyssaert S, Mertens J, et al. Phytoremediation prospects of willow stands on contaminated sediment: A field trial. Environ Pollut. 2003.126 (2): 275-282

Wang J, Xu H K and Guo S H. Isolation and characteristics of a microbial consortium for effectively degrading phenanthrene. Petroleum Science. 2007. 4(3): 68-75

Xu S Y, Chen Y X, Wu W X, et al. Enhanced dissipation of phenathrene and pyrene in spiked soils by combined plants cultivation. Science of Total Environment. 2006. 363: 206-215

(Edited by Zhu Xiuqin) 